\title{
Lack of evidence for an increased microchimerism in the circulation of patients with Sjögren's syndrome
}

\author{
I Toda, M Kuwana, K Tsubota, Y Kawakami
}

\begin{abstract}
Objective-To examine the hypothesis that fetal microchimerism plays a part in the pathogenic process of Sjögren's syndrome (SS).

Methods-Genomic DNA samples were extracted from peripheral blood whole nucleated cells and the CD34+ cell enriched fraction of patients with SS and healthy women who had male offspring as well as nulliparous women. A Y chromosome-specific sequence was detected as a marker for fetal cells by a nested polymerase chain reaction (PCR) and by DNA hybridisation combined with PCR using specific primers and probes. All procedures were performed with great care to avoid the contamination of male DNA.
\end{abstract}

Results-A nested PCR and DNA hybridisation combined with PCR was established that can detect a single male cell out of $1.67 \times 10^{5}$ female cells. It was not possible to increase the sensitivity further because the amount of template DNA held in the PCR was limited. When these methods were used, no fetal cells were detected in any samples from patients with SS, though they were detected in whole nucleated cells from two healthy women who had delivered sons previously.

Conclusions-The findings indicate that circulating fetal cells in patients with SS are uncommon $\left(<1\right.$ in $\left.1.67 \times 10^{5}\right)$, if they exist. With the conventional PCR based methods that were used, it is difficult to evaluate the quantitative difference in circulating fetal cells between patients with

Institute for Advanced Medical Research, Keio University School of Medicine, Tokyo,

Japan

I Toda

M Kuwana

Y Kawakami

Department of

Ophthalmology, Tokyo

Dental College, Japan

K Tsubota

Correspondence to:

Dr M Kuwana, Institute for Advanced Medical Research, Keio University School of

Medicine, 35 Shinanomachi,

Shinjuku-ku, Tokyo

160-8582, Japan

kuwanam@med.keio.ac.jp

Accepted 15 May 2000
SS and healthy women.

(Ann Rheum Dis 2001;60:248-253)

Sjögren's syndrome (SS) is an autoimmune disease characterised by lymphocytic infiltration into lachrymal and salivary glands, leading to a significant decrease in tear and saliva secretion. ${ }^{1}$ This disorder is associated with the production of various autoantibodies. ${ }^{23} \mathrm{Al}-$ though previous studies have shown that the pathogenic process of SS may be associated with numerous factors of viral, endocrine, neural, genetic, and environmental origin, ${ }^{4-7}$ the mechanism responsible for development of the disease still remains unclear.

Another consideration in understanding the cause of SS is the markedly higher incidence in women-more than nine times as common in women than in men. ${ }^{8} \mathrm{~A}$ number of studies have described the effect of sex hormones on the female predisposition of autoimmune diseases, including SS. ${ }^{5}{ }^{9-12}$ Androgens dramatically suppress lymphocytic infiltration in lachrymal and salivary glands of female MRL/lpr mice. ${ }^{11}$ In contrast, prenatal exposure to oestrogens in normal mice induced salivary gland lesions indistinguishable from SS and accelerated autoantibody production. ${ }^{10}$ However, the effect of these hormone actions is controversial. ${ }^{13}$ Thus sex hormones may be a risk factor for the development of SS, but hormonal influence alone is not sufficient to explain the female predominance in SS.

Another possible factor associated with the female predominance in SS is pregnancy. It is now evident that pregnancy is an important immunological event in the life of women. It has been recognised that non-self fetal cells migrate into the maternal circulation during pregnancy. ${ }^{14}$ Among these cells, fetal haematopoietic progenitor cells have been reported to persist in the maternal circulation for decades. ${ }^{15}$ Thus these mothers are in a condition of microchimerism, in which two genetically different cells co-exist in one person. ${ }^{16}$ Symptoms of SS are similar to those of chronic graft versus host disease (GVHD) caused by the chimeric condition after allogeneic stem cell transplantation (SCT). ${ }^{17} 18$ The characteristic hallmark shared by SS and chronic GVHD is progressive atrophy and dryness of the mucosal surface. ${ }^{19} 20$ A lachrymal or salivary gland biopsy sample from patients with chronic GVHD showed lymphocytic infiltration, similar to that found in SS.

Other autoimmune diseases that predominantly affect women after childbearing age and have clinical similarities to chronic GVHD include scleroderma and primary biliary cirrhosis. ${ }^{19} 21$ Recently, Nelson proposed the hypothesis that fetal microchimerism plays a part in the pathogenesis of scleroderma. ${ }^{22}$ In her theory, some cases of scleroderma in women with children are actually GVHD caused by fetal cells. This hypothesis was supported by two independent reports that described an increased incidence of circulating fetal cells and also detected fetal cells in skin lesions from female patients with scleroderma. ${ }^{23}{ }^{24}$ In this report, to examine the possible role of microchimerism in the development of SS, we have attempted to detect circulating fetal cells in patients with SS using carefully established polymerase chain reaction (PCR) based assays. 


\section{Patients and methods}

PATIENTS AND CONTROLS

Thirty female patients with SS who had delivered at least one son were enrolled in this study. All patients satisfied the European criteria for $\mathrm{SS}^{25}$ and had no additional collagen disease (primary SS). Eighteen healthy women who had sons and eight nulliparous women served as controls. These healthy women had no self reported autoimmune disease or history of previous blood transfusion. The mean age of the subjects at blood collection was 60 (range 36-68) in patients with SS, $47(34-56)$ in healthy women with sons, and $25(22-36)$ in nulliparous women. The mean period between delivery of a male child and blood sampling was 29.3 years $(3-50)$ in patients with SS and 18.1 years (7-24) in healthy women with sons $(p=0.01)$. One male healthy donor and a female SCT recipient from a male donor were used as positive controls in assays for the detection of male cells. Three women who had delivered male children within the past 24 hours were used to validate the sensitivity of our detection methods. Informed consent was obtained from all subjects before blood collection.

PREPARATION OF GENOMIC DNA

Peripheral blood whole nucleated cells were separated from $20 \mathrm{ml}$ heparinised venous blood in the presence of $0.6 \%$ dextran. CD34+ cells were enriched from peripheral blood mononuclear cells $\left(1-4 \times 10^{7}\right)$ by incubating with $4 \times 10^{7}$ magnetic beads coated with monoclonal antibody against human CD34 (Dynal, Oslo, Norway). In some samples, the collected cells were detached from the beads, stained with the FITC conjugated anti-CD34 antibody, and analysed on a FACScalibur flow cytometer (Becton Dickinson, Bedford, MA) to determine the efficiency of the technique. Genomic DNA was extracted from peripheral blood whole nucleated cells or a CD34+ cell enriched fraction by digestion with proteinase $\mathrm{K}$, followed by phenol extraction and ethanol precipitation.

NESTED PCR FOR DETECTION OF MALE CELLS

Male DNA was detected by amplifying genomic DNA by nested PCR with primers specific for a Y chromosome-specific gene, TSPY (testis-specific protein $\mathrm{Y}$ encoded). ${ }^{26} \mathrm{TSPY}$ is located on $\mathrm{Yp}$ and has no known homology with autosomal genes. The first PCR was conducted using a sense primer (5'-CTTCCACC TTCAGCCACCGCCTCCTCT-3') and an antisense primer (5'-CTGTTGTGCGC TGCCTTGACGACCCAG-3'). The first PCR comprised 40 cycles of 30 seconds at $95^{\circ} \mathrm{C}, 30$ seconds at $66^{\circ} \mathrm{C}$, and one minute at $72^{\circ} \mathrm{C}$. The reaction mixture contained template DNA $(1 \mu \mathrm{g}$, except as indicated otherwise), $2 \mu \mathrm{mM} \mathrm{MgCl}, 200 \mu \mathrm{mol} / 1$ each of dNTPs, 2.5 units of Ampli-Taq Gold (PerkinElmer Cetus, Foster City, CA), and $1 \mu \mathrm{mol} / 1$ of each of the sense and antisense primers in $50 \mu \mathrm{l}$ of total volume. The second amplification of 20 cycles was performed using $2 \mu \mathrm{l}$ of the first PCR product with a sense primer (5'-
AGCATTGCCTCCAGCCTGAA-3') and an antisense primer (5'-AGCGGTTGCGGT GCCTGTTG-3'). The PCR amplified products were subjected to electrophoresis on a $1.5 \%$ agarose gel, followed by ethidium bromide staining. All PCR experiments contained a negative control (without template DNA) and positive controls (male DNA and DNA from a female SCT recipient from a male donor). All procedures were performed with great care to avoid contamination by male DNA. For example, experiments were performed in an environment isolated from men and all reagents were freshly prepared in every experiment.

In some experiments the PCR products were directly sequenced on the ABI Prism 310 Genetic Analyzer (Applied Biosystems, Foster City, CA) using the BigDye Terminator Cycle Sequence Ready Reaction kit.

DNA HYBRIDISATION COMBINED WITH PCR FOR DETECTION OF MALE CELLS

The products of the first PCR were also applied to DNA hybridisation using digoxigenin labelled oligonucleotide probes specific for the TSPY sequence. The PCR products fractionated on an agarose gel were transferred onto a nylon membrane (Hybond-N+; Amasham Pharmacia Biotech, Piscataway, NJ) by capillary blotting and hybridised with the probes at $52^{\circ} \mathrm{C}$ overnight. A mixture of five probes corresponding to different portions of the TSPY gene (5'-GCCAGCCCAGC CCAG-3', 5'-CCCCAGCAGACCCGC-3', 5'CCCGCAGATCCCGCA-3'， 5'-AGGCACC GCAACCGC-3', and 5'-CTGCGGGTG CGGAG-3') was used to increase the sensitivity. The membrane was washed and then processed using a commercially available detection system (DIG DNA detection kit; Boehringer Mannheim, Indianapolis, IN).

\section{Results}

ESTABLISHMENT OF NESTED PCR AND DNA HYBRIDISATION COMBINED WITH PCR FOR DETECTION OF MALE CELLS

Because the number of male cells in the female circulation was expected to be low, it was necessary to increase the amount of template DNA in PCR as much as possible. To determine the amount of template DNA that gives the highest number of copies of the product of interest without changing the PCR efficiency, the first PCR was carried out using a mixture of serial amounts of background female genomic DNA (100 ng-10 $\mu \mathrm{g})$ and 10 ng male DNA as templates (fig 1). The amplification occurred at the same efficiency in the presence of $100 \mathrm{ng}, 300 \mathrm{ng}, 600 \mathrm{ng}$, and $1 \mu \mathrm{g}$ of background female DNA. When $\geqslant 2 \mu \mathrm{g}$ of template DNA was added to the tubes for PCR, the PCR amplification efficiency decreased. In view of this result, $1 \mu \mathrm{g}$ of genomic DNA was used as a template in the following experiments.

To assess the sensitivity of detection of male DNA, serial amounts of male DNA $\left(10^{-3}-10^{-10}\right.$ $\mu \mathrm{g})$ mixed with $1 \mu \mathrm{g}$ of female DNA were amplified in a nested PCR (fig 2). A Y 


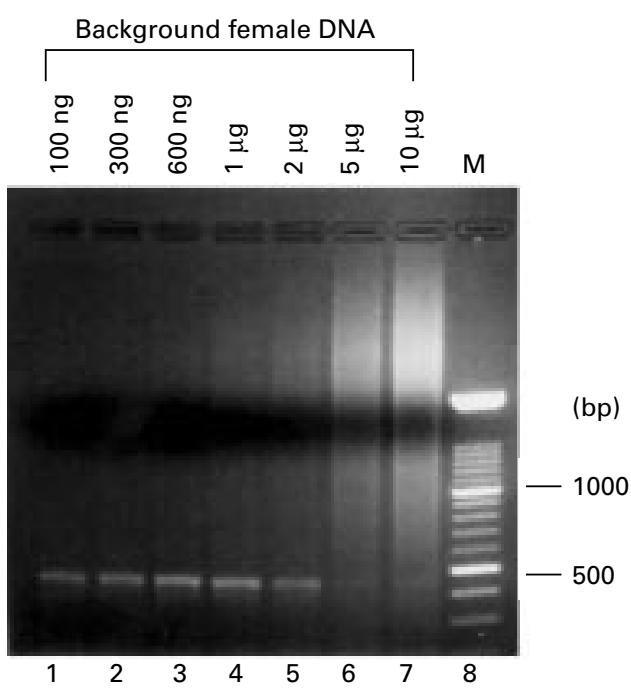

Figure 1 Amplification of the TSPY gene using male $D N A$ as a template in the presence of serial amounts of background female DNA. Serial amounts of female genomic DNA (100 ng-10 $\mu \mathrm{g})$ were mixed with $10 \mathrm{ng}$ male genomic DNA and used as templates for the first polymerase chain reaction (PCR). The PCR products were fractionated on a $1.5 \%$ agarose gel and stained with ethidium bromide. Lane 1: $100 \mathrm{ng}$, lane 2: $300 \mathrm{ng}$, lane 3: $600 \mathrm{ng}$, lane 4: $1 \mu \mathrm{g}$, lane 5: $2 \mu \mathrm{g}$, lane 6: $5 \mu \mathrm{g}$, and lane 7: $10 \mu \mathrm{g}$ of background female DNA. Lane 8: molecular weight markers (100 bp ladder).

chromosome-specific $345 \mathrm{bp}$ fragment was detectable when $\geqslant 10^{-7} \mu \mathrm{g}$ of male DNA was used as a template. PCR using $10^{-6} \mu \mathrm{g}$ and $10^{-7}$ $\mu \mathrm{g}$ of male DNA gave negative results in repeat experiments, whereas PCR using $\geqslant 10^{-5} \mu \mathrm{g}$ of male DNA constantly showed positive results. DNA sequencing confirmed that the $345 \mathrm{bp}$ fragment had a nucleotide sequence identical to that of the TSPY gene. To evaluate further the reliability of our detection system, a nested PCR was conducted using genomic DNA obtained from three women who had delivered sons within the past 24 hours. As shown in fig 3, a Y chromosome-specific product was detected in one of three samples.

The PCR products of the first PCR using serial amounts of male DNA were then hybridised with the TSPY probes. Positive signals were always detected when $\geqslant 10^{-5} \mu \mathrm{g}$ of male DNA was used in the first PCR (data not shown), indicating that the sensitivity for the detection of male DNA was similar for the nested PCR and the DNA hybridisation combined with PCR.

DETECTION OF FETAL CELLS IN CIRCULATING WHOLE NUCLEATED CELLS

Genomic DNA samples from peripheral blood whole nucleated cells of 18 patients with SS with sons, 12 healthy women with sons, and five healthy women with no sons were analysed by nested PCR (fig 4). Male cells in the circulation of previously pregnant women were considered as fetal cells. The experiment was repeated three times, but no fetal cells were detected in any samples.

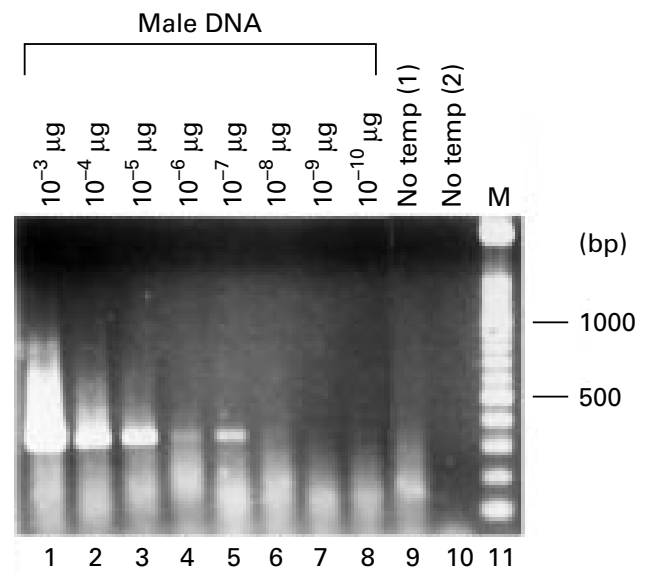

Figure 2 Detection of the TSPY gene by nested polymerase chain reaction (PCR) using serial amounts of male DNA as templates. Serial amounts of male DNA $\left(10^{-3}-10^{-10} \mu \mathrm{g}\right)$ in $1 \mu \mathrm{g}$ of female DNA were amplified by the nested PCR. The PCR products were fractionated on $1.5 \%$ agarose gel and stained with ethidium bromide. Lane 1: $10^{-3} \mu \mathrm{g}$, lane 2: $10^{-4} \mu \mathrm{g}$, lane 3: $10^{-5} \mu \mathrm{g}$, lane $4: 10^{-6} \mu \mathrm{g}$, lane 5: $10^{-7} \mu \mathrm{g}$, lane $6: 10^{-8} \mu \mathrm{g}$, lane $7: 10^{-9} \mu \mathrm{g}$, and lane 8 : $10^{-10} \mu \mathrm{g}$ of male DNA. Lane 9: no template for the first PCR and lane 10: no template for the second PCR. Lane 11: molecular weight markers (100 bp ladder).

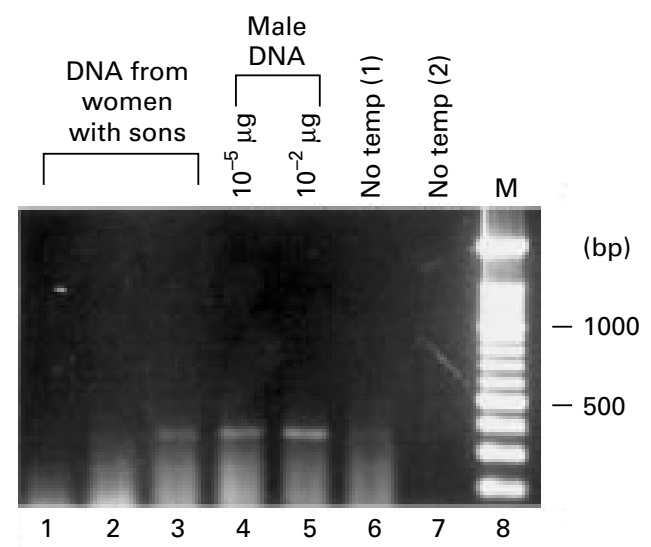

Figure 3 Detection of male cells in peripheral blood whole nucleated cells from women who had delivered sons within the past 24 hours by a nested polymerase chain reaction (PCR). Genomic DNA from peripheral blood whole nucleated cells obtained from three women one day after delivery (lanes 1-3: $1 \mu \mathrm{g}$ ), and control male DNA (lane 4: $10^{-5} \mu \mathrm{g}$ and lane 5: $10^{-2} \mu \mathrm{g}$ ) were applied for the nested PCR. The PCR products were fractionated on $1.5 \%$ agarose gel and stained with ethidium bromide. Lane 6: no template for the first PCR and lane 7: no template for the second PCR. Lane 8: molecular weight markers (100 bp ladder).

A DNA hybridisation combined with PCR was also carried out using the same DNA samples on three different occasions (fig 5). Fetal cells were detected in two healthy women with sons in one experiment, but these samples gave negative results in the other two experiments. No positive signal was detected in any samples from patients with SS in the three experiments.

DETECTION OF FETAL CELLS IN CIRCULATING CD34+ CELL ENRICHED FRACTION

The presence of fetal cells in the CD34+ cell enriched fraction from 10 patients with SS with sons, five healthy women with sons, and three healthy women with no sons was examined by 


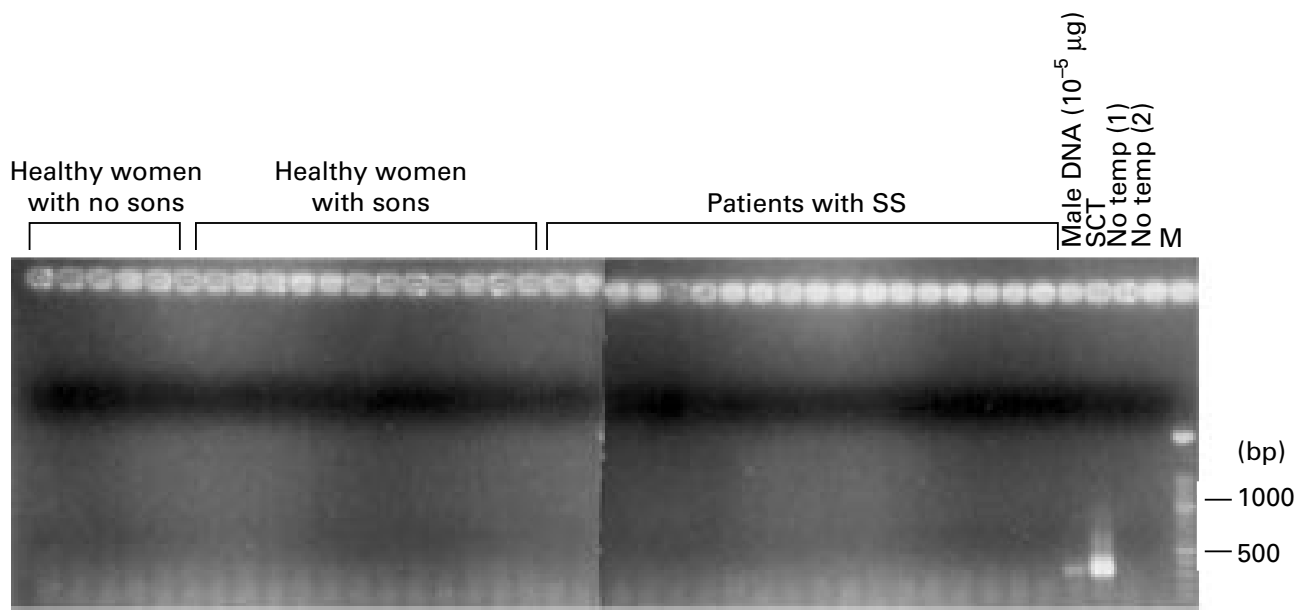

1223455677891011121314151617181920212223242526272829303132333435363738394041

Figure 4 Detection of male cells in peripheral blood whole nucleated cells from healthy women with no sons, healthy women with sons, and patients with $S S$ with sons by a nested polymerase chain reaction (PCR). Genomic DNA (1 $\mu g$ ) from these subjects was amplified by a nested PCR, and the PCR products were fractionated on 1.5\% agarose gel and stained with ethidium bromide. Lanes 1-6: healthy women with no sons, lanes 7-17: healthy women with sons, and lanes 18-36: patients with SS with sons. Lane 37: male DNA $\left(10^{-5} \mu \mathrm{g}\right)$, lane 38: DNA from a female stem cell transplantation (SCT) recipient from a male donor $(1 \mu \mathrm{g})$, lane 39: no template for the first PCR, and lane 40: no template for the second PCR. Lane 41: molecular weight markers (100 bp ladder).

a nested PCR and by DNA hybridisation combined with PCR. Flow cytometric analysis showed that the CD34+ cell enriched fraction obtained from two samples contained $10 \%$ and $12 \%$ CD $34+$ cells, indicating that CD $34+$ cells were enriched by at least 10 times. Fetal cells were detected in none of the samples either by the nested PCR or by the DNA hybridisation combined with PCR (data not shown).

\section{Discussion}

In this study we failed to obtain evidence to show that fetal microchimerism is increased in peripheral blood whole nucleated cells or the CD34+ cell enriched fraction of patients with SS using carefully established PCR based methods for the detection of male cells. Circulating fetal cells were detected in two healthy women with sons, but not in any patients with SS. Therefore, the incidence of fetal cells in the circulation was too low to assess a quantitative difference between patients with SS and healthy subjects by our methods.
It is unlikely that the failure to detect fetal cells in this study is due to the low sensitivity of our assays. We used $1 \mu \mathrm{g}$ of genomic DNA for the first PCR, because this was the maximum quantity that can be used in PCR as a template without inhibition of the amplification efficiency. One microgram of genomic DNA is equivalent to the amount of DNA that is contained in $1.67 \times 10^{5}$ cells, based on an assumption that a single cell contains approximately 6 pg of genomic DNA. ${ }^{27}$ Male DNA was constantly detected in the nested PCR using $\geqslant 10^{-5} \mu \mathrm{g}$ male DNA mixed with $1 \mu \mathrm{g}$ of background female DNA as templates. In contrast, a Y chromosome-specific product was sometimes detected when $<10^{-6} \mu \mathrm{g}$ of male cells was added in the PCR, probably because $1 \mu \mathrm{g}$ of genomic DNA contained male DNA by chance in these dilutions. This finding indicated that sensitivity of our nested PCR exceeded one male cell out of $1.67 \times 10^{5}$ female cells and, therefore, our nested PCR can detect a single

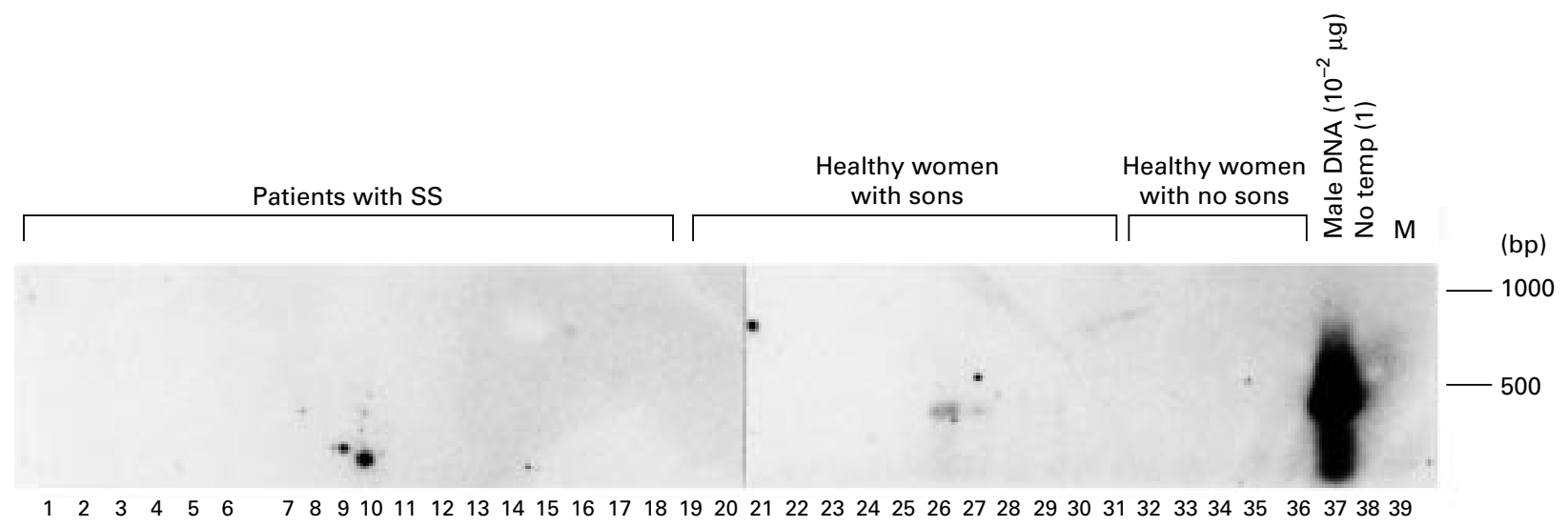

Figure 5 Detection of male cells in peripheral blood whole nucleated cells from patients with Sjögren's syndrome with sons, healthy women with sons, and healthy women with no sons by DNA hybridisation combined with a polymerase chain reaction (PCR). The PCR products of the first PCR were fractionated by electrophoresis and hybridised with probes specific for the TSPY gene. Reactivities were visualised with a chemiluminescence detection system. Lanes 1-18: patients with SS with sons, lanes 19-31: healthy women with sons, and lanes 32-36: healthy women with no sons. Lane 37: male DNA $\left(10^{-2} \mu \mathrm{g}\right)$ in the first PCR and lane 38: no template for the first PCR. Lane 39: molecular weight markers (100 bp ladder). 
male cell in $1.67 \times 10^{5}$ female cells. This sensitivity was confirmed by the finding that male DNA was detected in one of three women who had delivered sons within the past 24 hours; a previous report showed that fetal cells were often detected when $10^{5}$ nucleated cells from maternal peripheral blood were assessed one day after delivery. ${ }^{14}$ The sensitivity of the nested PCR was similar to the DNA hybridisation combined with PCR, and was comparable with that in a previously reported method for the detection of the $\mathrm{Y}$ chromosome-specific sequence. ${ }^{28}$ Therefore, our results indicate that circulating fetal cells, if they exist, are fewer than 1 out of $1.67 \times 10^{5}$ host cells in patients with SS and in healthy women who were previously pregnant.

Two recent reports showed that the incidence of fetal cells in peripheral blood from patients with scleroderma was higher than in blood from control women. ${ }^{23}{ }^{24}$ The discrepancy between our finding and these results may merely reflect the difference in the pathogenic process between scleroderma and SS, but it may be due to several problems in the methods they used for the detection of fetal cells. In fact, one recent report failed to confirm their results using the same detection method. ${ }^{29}$ These investigators used PCR based methods to detect the Y chromosome-specific sequence as a marker for fetal cells. The incidence of circulating fetal cells in their reports appeared to be less than one out of $10^{6}$ cells, though they did not mention the amount of genomic DNA used in the PCR as a template. Another problem is that the $\mathrm{Y}$ chromosome sequence was detected even in women who had no sons. ${ }^{30}$ Possibly, male cells or DNA contaminated the experiments. Nested PCR and PCR using radiolabelled nucleotides are so sensitive that they can detect even one copy of contaminating male DNA. Therefore, any contact with men and their belongings should be avoided in the experiments. We ourselves have sometimes obtained false positive results in negative control samples after repeated use of reagents, possibly due to contamination by male DNA, despite great care to prevent contamination.

To increase the sensitivity for detection of circulating fetal cells, a CD34+ cell enriched fraction was used in our assays, based on a previous finding that fetal CD34+ cells preferentially persist in maternal peripheral blood for decades after pregnancy. ${ }^{15}$ However, fetal cells were below the detectable level even when the CD34+ cell enriched fraction was used, though the number of samples examined was small. Recently, Evans et al showed that fetal DNA was detected in various subsets of peripheral blood mononuclear cells, such as T cells, B cells, NK cells, and monocytes, from some patients with scleroderma and healthy women. ${ }^{30}$ Taken together, our findings indicate that fetal cells are not concentrated in the CD34+ cell population, but, rather, are distributed in various subsets of maternal circulation after pregnancy.

The incidence of circulating non-self cells is expected to be low in patients with SS, if they exist $\left(<1\right.$ in $\left.1.67 \times 10^{5}\right)$, whereas cells derived from bone marrow are totally exchanged in patients with chronic GVHD after allogeneic SCT. Recently, we have found that ultrastructural findings in the lachrymal gland are significantly different between SS and chronic GVHD. ${ }^{31}$ Thus because of a remarkable difference in the number of effector cells and histological findings of these two diseases, the pathogenic process of SS and chronic GVHD may not be mediated by the same mechanism.

Is then the microchimerism theory for the development of SS totally irrelevant? The incidence of fetal cells in maternal peripheral blood is low whether the subjects have SS or not, but the possibility cannot be excluded that a significant difference might be found if more sensitive assays than the conventional PCR based methods were available and used. Because the incidence of fetal cells is influenced by the period since the last delivery, ${ }^{14}$ patients with SS might have had a higher incidence of fetal cells immediately after delivery. Moreover, it is still possible that a small number of fetal cells play a part in the pathogenesis of SS. Fetal cells may migrate preferentially into target organs of the disease rather than into the circulation. Artlett et al used fluorescence in situ hybridisation to identify a Y chromosome sequence in skin biopsy specimens from women with scleroderma who had male children. ${ }^{24}$ To date, fetal cells in lachrymal or salivary glands have not been examined in patients with SS, but a recent study analysing 10 liver specimens from women with primary biliary cirrhosis failed to detect the $\mathrm{Y}$ chromosome sequences in any samples. ${ }^{32}$ Another possibility is that antigenpresenting cells and immune regulatory cells derived from fetal haematopoietic stem cells disregulate the maternal immune system, resulting in induction and/or promotion of autoimmunity.

We thank Drs Nobuaki Ozawa and Yasunori Yoshimura for providing peripheral blood samples from women who gave birth to male children one day previously, and Ms Yuka Okazaki for assisting in the flow cytometric analysis.

This work was supported by the grants from the Japanese Ministry of Health and Welfare and from the Japanese Ministry of Education, Science, and Culture.

1 Anaya J, Talal N. Sjögren's syndrome and connective tissue diseases associated with other immunologic disorders. In: Koopman WJ, ed. Arthritis and allied conditions. Baltimore: Williams \& Wilkins, 1997:1561-80.

2 Herley JB, Alexander EL, Bias WB, Fox OF, Provost TT, Reichlin M, et al. Anti-Ro (SS-A) and anti-La (SS-B) in patients with Sjögren's syndrome. Arthritis Rheum 1986; 29:196-206.

3 Fox RI, Robinson CA, Curd JG, Kozin F, Howell FV. Fox RI, Robinson CA, Curd JG, Kozin F, Howell FV.
Sjögren's syndrome. Proposed criteria for classification. Arthritis Rheum 1986;29:577-85.

4 Fox RI, Pearson G, Vaughman JH. Detection of EpsteinBarr virus-associated antigens and DNA in salivary gland biopsies from patients with Sjögren's syndrome. J Immunol 1989;137:3162-8.

5 Homo-Delarche F, Fitzpatrick F, Christeff N, Nunez EA, Bach JF, Dardenne M. Sex steroids, glucocorticoids, stress and autoimmunity. J Steroid Biochem Mol Biol 1991;40: 619-37.

6 Fox R, Saito I. Sjögren's syndrome: immunologic and neuroendocrine mechanisms. Adv Exp Med Biol 1994;350: 609-21.

7 Sullivan D. Possible mechanisms involved in reduced tear secretion in Sjögren's syndrome. In: Homma M, Sugai S, Tojo T, Miyasaka N, Akizuki M, eds. Sjögren's syndrome. Tojo T, Miyasaka N, Akizuki M, eds. Sjögren's sy
State of art. Amsterdam: Kugler Press, 1994:13-19.

8 Beeson PB. Age and sex associations of 40 autoimmune disBeeson PB. Age and sex associations
eases. Am J Med 1994;96:457-62.

9 Schuurs AH, Verheul HA. Effects of gender and sex steroids Schuurs AH, Verheul HA. Effects of gender and sex steroids
on the immune response. J Steroid Biochem 1990;35:15772 
10 Ahmed SA, Aufdemorte TB, Chen JR, Montoya AI, Olove D, Talal N. Estrogen induces the development of autoantibodies and promotes salivary gland lymphoid infiltrates in normal mice. J Autoimmun 1989;2:543-52.

11 Ariga H, Edwards J, Sullivan DA. Androgen control of autoimmune expression in lacrimal glands of MRL/Mplpr/lpr mice. Clin Immunol Immunopathol 1989;53:499508.

12 Carlsten H, Nilsson N, Jonsson R, Backman K, Holmdahl R, Tarkowski A. Estrogen accelerates immune complex glomerulonephritis but ameliorates T cell-mediated vasculitis and sialadenitis in autoimmune MRL lpr/lpr mice. Cell Immunol 1992;144:190-202.

13 Ishimaru N, Saegusa K, Yanagi K, Haneji N, Saito I, Hayashi Y. Estrogen deficiency accelerates autoimmune exocrinopathy in murine Sjögren's syndrome through fas-mediated apoptosis. Am J Pathol 1999;155:173-81.

14 Hamada $H$, Arinamai T, Hamaguchi H, Kubo T. Fetal nucleated cells in maternal peripheral blood after delivery. Am J Obstet Gynecol 1994;170:1188-93.

15 Bianchi DW, Zickwolf GK, Weil GJ, Sylvester S, DeMaria MA. Male fetal progenitor cells persist in maternal blood MA. Male fetal progenitor cells persist in maternal blood for as long as 27 years
USA 1996;93:705-8.

16 Tyndall A, Gratwohl A. Microchimerism: friend or foe? Nature Med 1998;4:386-8.

17 Atkinson K. Chronic graft-versus-host disease. Bone Marrow Transplant 1990;5:69-82.

18 Sullivan KM. Graft-versus-host disease. In: Thomas ED, Blume KG, Forman SJ, eds. Hematopoietic cell transplantation. Oxford: Blackwell Science, 1998:515-36.

19 Lawley TJ, Peck GL, Moutsopoulos HM, Gratwohl AA, Deisseroth AB. Scleroderma, Sjögren's syndrome, and chronic graft-versus-host disease. Ann Intern Med 1977; 87:707-9.

20 Ogawa Y, Okamoto S, Wakui M, Watanabe R, Yamada M, Yoshino $\mathrm{M}$, et al. Dry eye after haematopoietic stem cell Yoshino $M$, et al. Dry eye after haematopoietic stem
transplantation. Br J Ophthalmol 1999;83:1125-30.

21 McFarianem IG, McFarianem BM, Haines AL, Williams R. Relationship between primary biliary cirrhosis and chronic Rraft versus host diseases: investigation of histocompatibility (HLA) antigenic determinants in biliary tract antigens. ity (HLA) antigenic determin
Clin Sci 1983;64:113-16.
22 Nelson JL. Maternal-fetal immunology and autoimmune disease. Arthritis Rheum 1996;39:292-4.

23 Nelson JL, Furst DE, Maloney S, Gooley T, Evans PC, Smith A, et al. Microchimerism and HLA-compatible relationships of pregnancy in scleroderma. Lancet 1998;351: 559-62.

24 Artlett CM, Smith JB, Jimenez SA. Identification of fetal DNA and cells in skin lesions from women with systemic sclerosis. N Engl J Med 1998;338:1186-91.

25 Vitali C, Bombardieri S, Moutsopoulos HM, Balestrieri G, Bencivelli W, Bernstein RM, et al. Preliminary criteria for the classification of Sjögren's syndrome. Results of prospective concerted action supported by the European Community. Arthritis Rheum 1993;36:340-7.

26 Vogel T, Schmidtke J. Structure and function of TSPY, the Y-chromosome gene coding for the "testis-specific protein". Cytogenet Cell Genet 1998;80:209-13.

27 Jeffreys AJ, Wilson V, Neumann R, Keyte J. Amplification of human minisatellites by the polymerase chain reaction: toward DNA fingerprinting single cells. Nucleic Acids Res 1988;16:10953-71.

28 Sahota A, Yang M, McDaniel HB, Sidner RA, Book B, Barr $\mathrm{R}$, et al. Evaluation of seven PCR-based assays for the analysis of microchimerism. Clin Biochem 1998;31:641-5.

29 Murata H, Nakauchi H, Sumida T. Microchimerism in Japanese women patients with systemic sclerosis [letter]. Lancet 1999;354:220.

30 Evans PC, Lambert N, Maloney S, Frust DE, Moore JM, Nelson JL. Long-term fetal microchimerism in peripheral blood mononuclear cell subsets in healthy women and women with scleroderma. Blood 1999;93:2033-7.

31 Ogawa Y, Yamazaki K, Kuwana M, Mashima Y, Nakamura Y, Ishida S, et al. A significant role of stromal fibroblasts in rapidly progressive dry eye in patients with chronic graft-versus-host disease. Invest Ophthalmol Vis Sci (in press).

32 Rubbia-Brandt L, Philippeaux MM, Chavez S, Mentha G, Borisch B, Hadengue A. FISH for $\mathrm{Y}$ chromosome in women with primary biliary cirrhosis: lack of evidence for leukocyte microchimerism. Hepatology 1999;30:821-2. 